\title{
Disproportionate International Contributions to Subspecialties of Neuroradiology in the American Journal of Neuroradiology
}

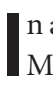
n a follow-up study to our article entitled, "Who's Contributing Most to American Neuroscience Journals: American or Foreign Authors?"1 we looked at the various branches of neuroradiology to identify the countries that contribute the most published articles to the American Journal of Neuroradiology (AJNR). We had shown that contributions to the AJNR by foreign institutions have dramatically increased in recent decades. ${ }^{1}$ We subsequently examined whether all areas of neuroradiology have been equally affected in the AJNR.

For this analysis, we assessed the country of the first author's institution in published articles in the past 30 AJNR issues (January 2016 to June 2018) to determine the contributions to Brain, Head \& Neck (H\&N), Spine, Neurointerventional Radiology (NIR), and Pediatrics (Ped) sections. In addition to calculating the percentage of US authorship, we determined which countries

We reviewed 793 articles. Overall, 350 (44.1\%) articles were from American institutions, and 443 (55.9\%) were from nonAmerican institutions. The percentages of articles from US institutions were $44.4 \%$ in $2016,47.2 \%$ in 2017 , and $37.4 \%$ from January to June 2018. The percentage of US authorship was least in NIR $(31.8 \% ; P<.001)$ and Brain $(41.5 \% ; P=.21)$, while it was significantly higher than non-US authorship in Spine $(60.7 \% ; P=$ $.002)$, followed by H\&N (53.7\%), and Ped (51.3\%) (Figure).

The foreign countries that had the highest contributions in Brain, H\&N, Spine, Ped, and NIR were Japan, Korea, Canada, Italy, and Germany, respectively (Table).

We concluded that contributions to the AJNR from non-US authors dominated in the NIR category, likely due to the more restrictive limitations of the FDA on new NIR devices compared with the more lenient oversight in Europe by their governmental bodies, such as the Medicines and Healthcare products Regulatory Agency in the United Kingdom and the French Organization for the Safety of Health Products. Asian countries may contribute more to $\mathrm{H} \& \mathrm{~N}$ due to the increased prevalence of thyroid and nasopharyngeal carcinomas and Epstein-Barr Virus infections. Europeans and Canadians publish more than those in Asian were contributing the most to each branch of neuroradiology.

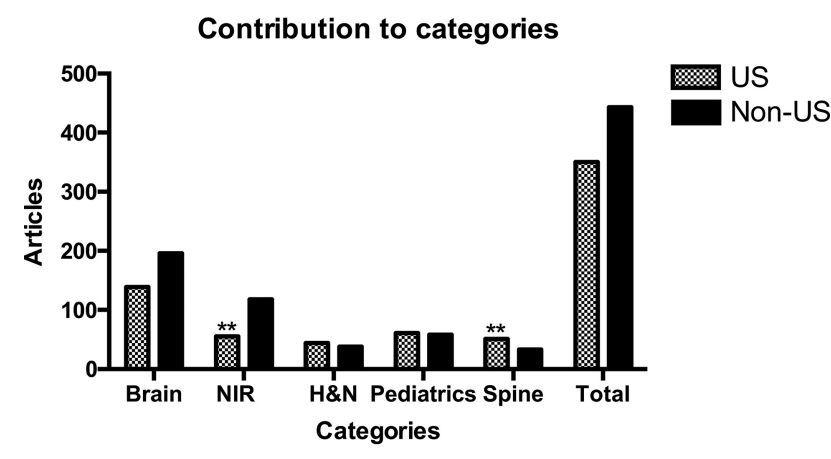

FIGURE. Contribution of US and Non-US countries to different subsections of the AJNR. Values are expressed as number of articles and were analyzed using the $\chi^{2}$ independence test. Double asterisks show $P<.01$ compared with the other groups.

countries in Pediatrics, in part from noteworthy Italian authorities in pediatric neuroradiology. The US prominence is foremost in the spine, and Canada dominates the non-US spine contributions. Overall, the contributions from non-US authors (55.9\%) exceeded those originating from the United States (44.1\%).

Disclosures: David M. Yousem—UNRELATED: expert testimony: medicolegal work; Payment for Lectures Including Service on Speakers Bureaus: American College of Radiology Education Center; Royalties: Elsevier, Comments: 5 books; Travel/Accommodations/Meeting Expenses Unrelated to Activities Listed: Radiological Society of North American Educator Career Award 2018.

\section{REFERENCE}

1. Charkhchi P, Mirbolouk M, Jalilian R, et al. Who's contributing most to American neuroscience journals: American or foreign authors? AJNR Am J Neuroradiol 2018;39:1001-07 CrossRef Medline

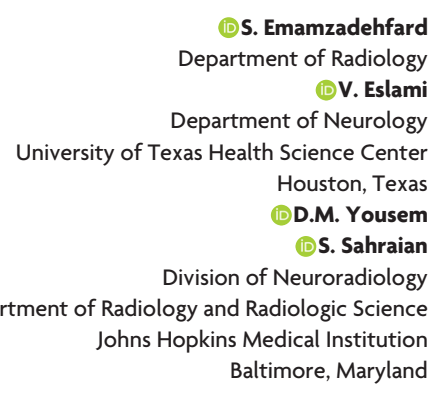

(1)S. Emamzadehfarc V. Eslami Department of Neurology D.M. Yousem (D)S. Sahraian The Russell H. Morgan Division of Neuroradiology Johns Hopkins Medical Institution 
Top 2 foreign countries with highest contributions to subsections of AJNR

\begin{tabular}{llccr}
\hline Specialty & $\begin{array}{c}\text { Top Country } \\
\text { Contributor }\end{array}$ & $\begin{array}{c}\text { Top Country (No. of } \\
\text { Articles) (\% of Non-US) }\end{array}$ & $\begin{array}{c}\text { No. 2 Country } \\
\text { Contributor }\end{array}$ & $\begin{array}{c}\text { No. 2 Country (No. } \\
\text { of Articles) (\% of Non-US) }\end{array}$ \\
\hline Brain & Japan & $28(14.3 \%)$ & China & $24(12.2 \%)$ \\
H\&N & Korea & $15(39.5 \%)$ & China & $6(15.8 \%)$ \\
NIR & Germany & $22(18.6 \%)$ & France & $19(16.1 \%)$ \\
Pediatrics & Italy & $12(20.6 \%)$ & Canada & $8(13.8 \%)$ \\
Spine & Canada & $10(30.3 \%)$ & Switzerland & $4(12.1 \%)$ \\
\hline
\end{tabular}

